Editorials

\title{
Importance of Comparative Psychology in Pet Industry Litigation
}

\author{
Charles I. Abramson and Timothy E. Black \\ Department of Psychology, \\ Laboratory of Comparative Psychology and Behavioral Biology, Oklahoma State University, USA
}

\author{
Article history \\ Received: 12-06-2017 \\ Revised: 20-06-2017 \\ Accepted: 29-08-2017 \\ Corresponding Author: \\ Charles I. Abramson \\ Department of Psychology, \\ Laboratory of Comparative \\ Psychology and Behavioral \\ Biology, Oklahoma State \\ University, USA \\ Email: charles.abramson@okstate.edu
}

\begin{abstract}
Comparative psychology is the branch of psychology that studies animal behavior. This article describes the value of comparative psychology for pet industry litigation. An overview is provided on the unique strengths and skills of a comparative psychologist and how comparative psychology differs from other scientific disciplines interested in the behavior of animals. In addition, examples are provided on how comparative psychology can be applied to litigation in the pet industry. Information is also provided on the training of comparative psychologists and where comparative psychologists can be found.
\end{abstract}

Keywords: Comparative Psychology, Pet Industry, Litigation

\section{Introduction}

The pet industry is a multibillion dollar enterprise with sales of products and services projected to be $\$ 62.75$ billion dollars in 2016 (APPA, 2016). Unfortunately much of the data on the amounts pet companies spend on related litigation is unavailable. Major outlets such as the American Bar Association, Pet Industry Magazine, Pet Business Magazine and Sundale Research for example, do not keep such statistics. A recent survey of Fortune 200 companies acknowledged that there are few empirical studies documenting legal costs across disciplines (U.S. Chamber Institute for Legal Reform, 2010). The lack of empirical data as opposed to anecdotal evidence is suggested to be due, in part, because of confidentiality agreements

As a result of cases settled out of court and subject to confidentiality agreements, it must be noted that, like the lack of data on how much is spent on pet industry litigation, there are no published accounts of specific cases where a comparative psychologist has been called to testify during a trial. All of the cases that the senior author has been involved with, have been subject to confidentiality agreements. Occasionally, as in cases of class action suits brought against major companies like Big Heart Pet Brands, Blue Buffalo Company (Ltd.), Nutro Products, and Tyson Foods Inc.-Animal Nutrition Group, such litigation is brought to the attention of the public, the largest of which resulted in a settlement of 24 million dollars and subsequent FDA regulatory reform of the industry (Paulman, 2008). In addition to lawsuits, companies face regulation, recalls and product liability claims. While many of these cases surround products produced by major companies, some involve the ethical treatment of animals by public organizations. In the case of Daskalea v. Washington Humane Society, for example, the issue was not a product harming an animal, but the organization itself (Daskalea v. Washington Humane Society, 2010). The purpose of this paper is to bring to the attention of legal professionals the contributions that comparative psychology can make to the field of pet litigation.

No case in the pet industry field has gone to trial in which a comparative psychologist has been called as an expert witness. While there is no direct precedent for consulting a comparative psychologist as an expert witness, many legal teams have called upon psychologists to offer testimony on subjects in which they are knowledgeable. These cases include domestic abuse (New Hampshire v. Baker, 1980), custody disputes (Painter v. Bannister, 1966), and perhaps most notably, cases involving the insanity defense (Clark v. Arizona, 2006; United States v. Salvia, 1992). The precedents set by the use of clinical psychologists as expert witnesses lends support to the use of comparative psychologists as a source of valuable information regarding animals, their behavior and interactions with humans, and the products that are supplied to them.

This article will highlight the application of comparative psychology to pet industry litigation and 
seeks to encourage those in the legal professions and pet industries to consult comparative psychologists. This paper will explore the strengths and skills of a comparative psychologist, the advantages over other professions that examine animal behavior, what it takes to become a comparative psychologist, and how such a psychologist can address issues in the pet industry.

Comparative psychology can be defined as the application of the comparative method to problems in psychology (Abramson, 2015). A major emphasis in comparative psychology is the study of animal behavior both within and between species and subspecies. Depending on the history one reads, it is considered the first form of psychology, and has as its founders and adherents, Aristotle, M. E. Bitterman, Charles Darwin, Pierre Flourens, C. Lloyd Morgan, Ivan Pavlov, George Romanes, B. F. Skinner, Ethel Tobach, Margaret F. Washburn, and John B. Watson (Jaynes, 1969; Lockard, 1971; Dewsbury, 1984). Indeed, in his summary of the field, Greg Moran stated that comparative psychology is a field uniquely focused on issues regarding interaction with, and maintenance of, animals of all kinds (Moran, 1987) suggesting it has a place in the legal proceedings regarding these interactions. For readers interested in the history of comparative psychology there is an on-line resource: http://comparativepsych.wixsite.com/mysite.

\section{Applicability of Comparative Psychology to Litigation}

Comparative psychology has much to recommend it for pet industry litigation. It is arguably the only psychological discipline where one is explicitly trained to make direct comparisons. It may be argued that all psychologists are trained to make comparisons, but given the recent revelations about the problems of replication, there is room for doubt (Grice et al., 2012; Bohannon, 2015; Hubbard, 2015). One may pose the question "why should we use comparative psychology, when other systems for examining behavior, such as ethology, exist?" The answer is simple. Other sciences that focus on behavior, often fail to take into account the psychological perspective and frankly do not have the necessary psychological training. Ethology, for example, focuses almost exclusively on behavior expressed under natural conditions with a goal of understanding the evolutionary history and adaptivity of behavior (Lorenz, 1981). Sociobiology, another science that is interested in animal behavior focuses primarily on social behavior and its underlying evolutionary and genetic components (Alcock, 2001). Although the fields of Ethology and Sociobiology have both made major contributions to the study of behavior, proponents have little or no formal training in the psychology of pets nor the interactions of pets and their human companions.
A comparative psychologist bridges the gap between Ethology and Sociobiology. Comparative psychologists brings an understanding of behavior, both human and animal, and its multitude of potential underlying causes to the analysis of any legal argument. Comparative psychology, unlike other behavioral sciences, is able to approach pet industry litigation with psychological expertise in many areas of interest including human-pet interactions, product testing, assessment of emotional aspects of a product on its user, and evaluating the effectiveness of enrichment devices on pets and farm animals. Moreover, unlike other disciplines that study animal behavior, comparative psychologists are trained as psychologists. An ethologist, socio-biologist, and zoologist all study behavior but they are inadequate if the evidentiary basis of the litigation is psychological such as human-pet interactions, animal depression, and pet custody disputes.

Comparative psychologists are well versed in experimental design. In the normal course of their work, they routinely use such fundamental building blocks of experimental design as independent and dependent variables, control variables, analogies, homologies, statistical analyses and systematic variations. It is worth noting that analogies and homologies hold specific relevance to pet industry litigation, as they are defined as behaviors of a common function, or of a common ancestral descent respectively (Wenzel, 1992).

Comparative psychologists routinely use descriptive designs (known as behavioral profiles or ethograms), correlational designs, and experimental designs including quasi-experimental designs. Indeed, it can be concluded that the majority of a comparative psychologist's qualifications to serve on a litigation team stems from this set of skills. The ability of a comparative psychologist to examine behaviors, and subsequently make comparisons between and among species is all due to the rigorous training in experimentation that is required for an advanced degree. For example, consider a common example in the pet industry where the use of "systematic variation" would be of value to in litigation. In an experiment suggesting the superiority of one type of treat over another an advertisement might claim that four out of five cats prefer treat "A" over treat "B". A comparative psychologist would point out that such a claim is meaningless if, for example, the study has a limited age range, a single sex, and/or one breed of cat is tested. Age, sex, breed, and other factors, must be "systematically varied" before such a claim can be made. A comparative psychologist in this instance can offer litigators information and suggestions concerning new or ongoing research, and in the case of improving the evidentiary basis of a case, bring to light potentially overlooked factors in a company's testing and development procedures. 
Comparative psychologists have uncovered many species and subspecies differences which lead to the conclusion that it is difficult to generalize across subspecies. One study noted differences in the ability of dogs to respond to hand gestures based on breed (Wobber et al., 2009). Likewise, examination of anxiety across dog breeds revealed that there are significant variations based on the breed of dog studied (Mahut, 1958). Yet another study, conducted on cattle, noted direct changes in feeding behavior based on the breed (Schenkel et al., 2004). Thus companies making generalized claims such as "most pets prefer" or nine out of ten dogs prefer" open themselves up to suits regarding deceptive advertising.

Second only to their expertise in research design, comparative psychologists are trained to make valid comparisons, and expose invalid ones. Consider, for example, a recent study by Halos et al. (2015) the title of which is "Preference of dogs between two commercially available oral formulations of ectoparasiticide containing isoxazolines, afoxolaner or fluralaner" A comparative psychologist would immediately point out that such a title is potentially misleading. Further analysis of the article revealed that only beagles were examined. It is not logical, nor experimentally sound, to extend the results obtained with a beagle, to other dog breeds without adequate experimentation. To generalize this to a human example, it would be similar to collecting data from the Ponca Tribe in Oklahoma, and claiming that it was representative of all Native Americans. There is a further issue of ecological validity, as the behaviors of animals are often specific to their environment. For example, a study by Blanchard et al. (1986) noted marked differences between fear responses in a comparison of laboratory raised and wild caught rats. What was needed in the Halos et al. (2015) study was a group examined under "in-home" conditions. Finally, the study used beagles that had been the subject of previous drug trials. Clearly, there is potential for the results to have been compromised by the dogs' previous history of drug use. Other questions that might compromise results in Halos et al. (2015) include the type of testing method (some methods being more valid than others given the circumstances of the study), issues related to age and weight of test subjects, what kind of products were evaluated on the animals prior to the administration of the test product (known as subject variables). These and many other questions are the type asked by comparative psychologists.

To further highlight the niche filled by comparative psychologists, consider the comparison of a general psychologist, comparative psychologist, and an ethologist. All three have interest and experience in research and uncovering fundamental issues related to the analysis of behavior. The ethologist typically focuses on observational research with little attention paid to human-pet interactions. Conversely, the general psychologist works almost exclusively with humans, offering little insight into how behavior varies across and within species. In juxtaposition to the two, the comparative psychologist explores behavioral variations within and between species and possesses the extensive research tools to make valid conclusions.

Consider what goes into designing a single experiment comparing a cat and a dog. First, does it make sense to make such a comparison? What should be compared - is the behavior we are comparing between the two species analogous or homologous, how are rewards or punishment equated across the two species, what apparatus should be used? If a difference is found, is the difference qualitative and not based on differences in motivation, sensory ability, subject variables such as age or sex, rewards and testing protocols? As such, once a difference is detected, possible explanations must be systematically varied to ensure that difference is real and not simply based on quantitative variations.

The ability to answer these kinds of questions and to evaluate them experimentally is one of the hallmarks of comparative psychology. Comparative psychologists are able to answer questions in depth, and ensure that the results can be replicated. In the pet industry this type of comparative work can be used to improve and evaluate a product, explore a product's generalizability from laboratory to field, appraise the preference of a product over a competitor, and determine why one product is selected by an animal (or human) over another. An in depth comparative analysis offers direct benefit to those involved in litigation as proper evaluations and the understanding and interpretation of experimental designs can bolster, or even pre-empt, many legal cases before they proceed to trial.

Given all these abilities, one may make the logical conclusion that a comparative psychologist's greatest benefit to litigation is in expert testimony. Psychologists, have often been brought into courts to provide testimony on mental and behavioral disorders (Myers, 1992), emotional state, and psychological testing (Greenberg et al., 2003). In all of these cases, the role of the psychological expert witness is to provide clarification of definitional issues, clinical and experimental evaluations, and scientific assessment of the issue at hand (Myers, 1992). While such cases exist for many types of litigation, no case has gone to trial in which a comparative psychologist has been called to act as such a witness. Therefore, the body of existing literature that can explore the usefulness of a comparative psychologist to litigation teams is understandably small. To further explore the value of comparative psychology in pet industry litigation some potential legal situations in which a comparative psychologist might be called to act as such a witness will now be considered. 
Walker et al. (1997) present anecdotal evidence for the treatment of phobias and anxiety in dogs by oral medication. Suppose that a dog owner after reading the article (and/or the various advertisements touting the benefits of antidepressant medication for pets) administers amitriptyline and sees little or no improvement. The dog owner may file suit against the authors of the study and the manufacturer of amitriptyline claiming that the analysis of the authors and the product's effectiveness was unreliable if not outright false and dangerous. Here, a comparative psychologist's experimental skills and cross-species experience are exemplified. In such a case, a comparative psychologist unlike an ethologist or sociobiologist, could provide operational definitions for revealing anxiety in dogs and how this definition relates to the definitions of depression in humans. It may be a surprise for readers to lean that there are no generally accepted definitions of such human psychological disorders as anxiety, depression, separation anxiety, compulsive disorder, and cognitive dysfunction. If there are no generally accepted definitions for human psychological problems it cannot be claimed that any medication can solve these problems in pets. Medication to relieve cognitive dysfunction is especially problematic as there is no generally accepted definition of cognition. In a recent study surveying 9 popular introductory psychology and cognitive psychology textbooks, each textbook provided a different definition of cognition (Abramson, 2013). How can a medication state that it improves cognitive function in dogs if there is no generally accepted definition of cognition - the answer is that it cannot.

An analysis of behavioral definitions forms a central theme of comparative psychology and is often overlooked in litigation. Definitions of behavior, intelligence, and the procedures used to measure these behaviors are often inconsistent. This becomes important in pet litigation as products may claim to increase intelligence, cognitive function, or even improve behavior. Consider that there is no consistent definition of the word "behavior" among behavioral biologists (Cvrčková et al., 2016; Levitis et al., 2009). That any product may claim to alter an animal's behavior when little scientific consensus exists as to what is behavior is startling. Psychologists have sought to bring consensus to the scientific community on such definitions, not only for the term behavior, but also intelligence (Sternberg and Detterman, 1986; Legg and Hutter, 2007). Even the definitions of learning procedures associated with Pavlovian and operant conditioningare inconsistent (Abramson, 1994).

The case of Houseman v. Dare (2009) is another illustration of the potential value of a comparative psychologist to pet industry litigation. Here, the custody of a pet dog was in dispute after both parties separated. In this case, both parties urged the court to find in the manner that would be "best for the animal." Such a case mirrors that of many custody disputes regarding children, such as Painter v. Bannister (1966) in which two psychologists were brought in as expert witnesses to assess the home conditions posed by the parties vying for custody. A comparative psychologist, unlike an ethologist or sociobiologist, has the ability to do much the same regarding the well-being of pets under custody disputes. Under the circumstances presented by Houseman v. Dare (2009), a comparative psychologist could provide empirical evidence based on experiments as to which environment would be more beneficial to the pet. Moreover, a comparative psychologist could examine the animal's behavior, and offer insight, based on empirical evidence, to determine which party the animal would most prefer to remain with.

The previous two cases were concerned with the effectiveness of pet "psychotherapy" and pet custody issues, respectively. Now consider Heiligmann v. Rose (1891) a precedent setting case which gave rise to the practice of paying economic damages when an animal can no longer perform its function. According to the ruling in Heiligmann v. Rose, this "fair market value" encompasses not only what price was paid for the animal, but also the value of any services the animal provided to their owners. Here again, having expert testimony from a comparative psychologist is of benefit. A comparative psychologist may assess, based on either previous observation of the animal, accounts of its former skills, and/or empirically derived evidence, whether or not an injury has impaired its ability to perform tasks that it was purchased to perform.

\section{Additional Skills}

In addition to research skills, comparative psychologists by their very training have advanced critical thinking skills, a cultivated world view, and a set of real world problem solving abilities (White, 2007). Unlike in other types of psychology, comparative psychologists can be found in a wide range of applied fields in addition to academia. These fields include agriculture, animal-human interaction, "pet psychology", reproduction and reintroduction of endangered species and zoological gardens, even extending as far as robotics. In addition to a wide range of applications, comparative psychologists make use of many species in their research, far beyond the traditional white laboratory rats and pigeons (Papini, 2010). The wide range of skills, and experiences that go into the training of a comparative psychologist, along with the core skills required in the field, ensure that a comparative psychologist would be of value to any litigation team.

Unlike clinical psychologists and psychiatrists who typically come from graduate programs that are 
accredited by the American Psychology Association or the American Psychiatric Association respectively, and must pass state licensure requirements before they are allowed to practice unsupervised, comparative psychologists have no such formal requirements. The question naturally arises how do comparative psychologists become qualified. Typically, training in comparative psychology starts at the undergraduate level. Following completion of a bachelor's degree in psychology, students interested in advanced training apply to a graduate program in comparative psychology with the goal of obtaining a $\mathrm{PhD}$. The $\mathrm{PhD}$ may take anywhere from four to seven years of advanced training. Following successful completion of coursework, qualification and comprehensive examinations, dissertation and dissertation defense, the student is now qualified as a comparative psychologist.

Conducting ethical research and the ethical treatment of animals forms a major part of the training of a comparative psychologist. No experiment can be performed without approval of an Institutional Animal Care and Use Committees (IACUC) of the host organization. The training, which includes such courses as reducing pain and stress and proper handling procedures must be taken by all professors, students, and care givers who work with animals. Moreover, the course must be taken every three years. The IACUC training is designed to comply with the Animal Care Act of 1966. This is the only federal law in the United States that governs the treatment of animals in research.

Several organizations provide applied animal behavior certificates. These organizations include the ABI (2017) and the ABS (2014). Certified animal behavior specialists come from a variety of backgrounds including biologists, ethologists, psychologists, veterinarians, and zoologists. However, none of these courses offer a concentration in comparative psychology.

\section{Discussion and Conclusion}

Comparative psychologists have a unique set of evaluative skills should be part of any pet litigation team. Comparative psychologists can provide not only critical evaluations of pet industry experimental designs and analysis, but also help design experiments to evaluate pet products and human-pet interactions. Comparative psychology is uniquely suited to the field of pet litigation.

Industry officials seeking a comparative psychologist may want to contact them directly, or use a "subject matter expert program", which are often hosted by professional organizations like the American Psychological Association (APA). Division 6 of the APA maintains a list of comparative psychologists.

\section{Funding Information}

This article was funded in part by grants NSF-REU (2016-1560389), NSF-OISE (2015-1545803).

\section{Author Contributions}

Charles Abramson: Drafted the paper.

Timothy Black: Assisted in editing and revision.

\section{Conflict of Interest}

There is no conflict of interest to declare.

\section{References}

ABI, 2017. Animal Behavior Institute.

Abramson, C.I., 1994. The Primer of Invertebrate Learning: The Behavioral Perspective. Washington, DC: American Psychological Association, pp: 273.

Abramson, C.I., 2013. Problems of teaching the behaviorist perspective in the cognitive revolution. Behav. Sci., 3: 55-71. DOI: 10.3390/bs3010055

Abramson, C.I., 2015. A crisis in comparative psychology: Where have all the undergraduates gone? Front. Psychol., 6: 1500. DOI: $10.3389 /$ fpsyg.2015.01500

ABS, 2014. Certification Requirements and Application.

Alcock, J., 2001. The triumph of sociobiology. Oxford, United Kingdom: Oxford University Press.

APPA, 2016. Pet Industry Market Size and Ownership Statistics.

Blanchard, R.J., K.J. Flannelly and D.C. Blanchard, 1986. Defensive behaviors of laboratory and wild Rattus norvegicus. J. Comp. Psychol., 100: 101-107. DOI: 10.1037/0735-7036.100.2.101

Bohannon, J., 2015. Many psychology papers fail replication test. Science, 349: 910-911. DOI: $10.1126 /$ science. 349.6251 .910

Clark v. Arizona, 2006. 26 S.Ct. 2709.

Cvrčková, F., V. Žárský and A. Markoš, 2016. Plant studies may lead us to rethink the concept of behavior. Front. Psychol., 7: 622.

DOI: $10.3389 /$ fpsyg.2016.00622

Daskalea v. Washington Humane Society, 2010. 710 F.Supp.2d 32.

Dewsbury, D., 1984. Comparative psychology in the twentieth century. Stroudsburg, Pa.: Hutchinson Ross Inc.

Greenberg, S.A., R.K. Otto and A.C. Long, 2003. The utility of psychological testing in assessing emotional damages in personal injury litigation. Assessment, 10: 411-419.

DOI: $10.1177 / 1073191103259532$ 
Grice, J.W., P.T. Barrett, L.A. Schlimgen and C.I. Abramson, 2012. Toward a brighter future for psychology as an observation oriented science. Behav. Sci., 2:1-22. DOI: 10.3390/bs2010001

Halos, L., D.S. Carithers, R. Solanki, H. Stanford and S.J. Gross, 2015. Preference of Dogs between two commercially available oral formulations of ectoparasiticide containing isoxazolines, afoxolaner or fluralaner. Open J. Vet. Med., 5: 25-29. DOI: $10.4236 /$ ojvm.2015.52004

Heiligmann v. Rose., 1891. 16 S.W. 931.

Houseman v. Dare., 2009. 966 A.2d 24.

Hubbard, R., 2015. Corrupt research: The case for reconceptualizing empirical management and social science. Thousand Oaks, CA: Sage Publications.

Jaynes, J., 1969. The historical origins of 'ethology' and 'comparative psychology'. Anim. Behav., 17: 601-606. DOI: 10.1016/S0003-3472(69)80001-1

Legg, S. and M. Hutter, 2007. A collection of definitions of intelligence. Fr. Art. Int., 157: 17-24.

Levitis, D.A., W.Z. Lidicker G. Freund, 2009. Behavioural biologists do not agree on what constitutes behaviour. Anim. Behav., 78: 103-110. DOI: 10.1016/j.anbehav.2009.03.018

Lockard, R.B., 1971. Reflections on the fall of comparative psychology: Is there a message for us all? Am. Psychol., 26: 168-179.

DOI: $10.1037 / \mathrm{h} 0030816$

Lorenz, K.Z., 1981. The foundations of ethology. Berlin, Germany: Springer Science and Business Media.

Mahut, H., 1958. Breed differences in the dog's emotional behaviour. Can. J. Exp. Psychol., 12:35-44. DOI: $10.1037 / \mathrm{h} 0083722$

Moran, G., 1987. Applied dimensions of comparative psychology. J. Comp. Psychol., 101:277-281. DOI: 10.1037/0735-7036.101.3.277

Myers, J.E., 1992. Expert testimony describing psychological syndromes. Pacific Law J., 24: 1449-1464.
New Hampshire v. Baker, 1980. 120 N. H. 773.

Painter v. Bannister., 1966. 140 N.W.2d 152.

Papini, M.R., 2010. Comparative psychology: Evolution and development of behavior. Abingdon, United Kingdom: Psychology Press.

Paulman, K., 2008. See spot eat, see spot die: The pet food recall of 2007. Animal Laws, 15: 113-139.

Schenkel, F.S., S.P. Miller and J.W. Wilton, 2004. Genetic parameters and breed differences for feed efficiency, growth, and body composition traits of young beef bulls. Can. J. Anim. Sci., 84: 177-186. DOI: $10.4141 / \mathrm{A} 03-085$

Sternberg, R.J. and D.K. Detterman, 1986. What is intelligence? Contemporary viewpoints on its nature and definition. Norwood, NJ: Ablex.

U.S. Chamber Institute for Legal Reform, 2010. Litigation cost survey of major companies in conference on civil litigation.

United States v. Salvia, 1992. 503 US 569.

Walker, R., J.Fisher and P. Neville, 1997. The treatment of phobias in the dog. Appl. Anim. Behav. Sci., 52:275-289.

Wenzel, J.W., 1992. Behavioral homology and phylogeny. Ann. Rev. Ecol. Syst., 23:361-381. DOI: $10.1016 / \mathrm{S} 0168-1591(96) 01128-8$

White, D.A., 2007. Comparative psychology's relevance to a liberal arts education and personal development. Int. J. Comp. Psychol., 20: 13-19. DOI: 10.1146/annurev.es.23.110192.002045

Wobber, V., B. Hare, J. Koler-Matznick, R. Wrangham and M. Tomasello, 2009. Breed differences in domestic dogs' (Canis familiaris) comprehension of human communicative signals. Interact. Stud., 10:206-224. DOI: 10.1075/is.10.2.06wob 